\title{
NEURODEGENERATIVE DISEASES AND TAU: PATHOLOGICAL EVENTS AND MOLECULAR TARGETS
}

\author{
PIERFAUSTO SENECI (*) \\ Nota presentata dal m.e. Stefano Maiorana \\ (Adunanza del 29 novembre 2012)
}

SuNTO. - La proteina neuronale tau, e le malattie neurodegenerative da essa causate (taupatie), sono il cuore di questo contributo. Tau è descritta come proteina strutturalmente disordinata, attraverso i suoi domini e le sue sei isoforme. Le mutazioni di tau note, e le loro conseguenze sulla funzionalità di tau (distacco dai microtubuli, aggregazione di tau in oligomeri solubili e poi in aggregati insolubili) sono elencate ad introdurre le taupatie ad esse riferibili. E' descritta la natura e la frequenza di modifiche post-traslazionali della proteina, spiegando il loro impatto - quando la regolazione fisiologica è alterata - sulla conformazione di tau e sulla sua localizzazione, seguite dall'aggregazione patologica. Nel dettaglio, sono descritte la fosforilazione (regolatore negativo - inibizione necessaria), la glicosilazione con $\mathrm{N}$-acetilglucosammina e l'isomerizzazione cis-trans dell'epitopo pT231-P232 (regolatori positive - stimolazione necessaria), spiegandone la connessione con le anomalie biochimiche di tau, e lo sfruttamento come target molecolari per l'identificazione di piccole molecole capaci di prevenire o bloccare l'avanzamento delle taupatie.

ABSTRACT. - The neuronal protein tau, and the related neurodegenerative diseases named tauopathies, are thoroughly described here. Tau is characterized in terms of its disorganized structure, of its isoforms, and of its structural domains. Tau mutations,

Milan, Italy.

E-mail: pierfausto.seneci@unimi.it 
and their consequences on the functions of tau (detachment from microtubules, aggregation into soluble oligomers and insoluble aggregates), are mentioned to introduce a set of $\approx 30$ tauopathies. The pattern of post-translational modifications of tau is described, to explain its impact - when disregulated - on the folding and mislocalization of tau, followed by its aggregation. In details, tau hyper-phosphorylation (negative regulator, to be inhibited), N-Acetylglucosamine glycosylation and pT231-P232 cis-trans isomerization (positive regulator, to be stimulated) are described in terms of their connection to tau biochemical abnormalities, and of their exploitation as tauopathy-directed molecular targets.

\section{EPIDEMiology}

If one looks at life expectancy, we seem to be moving in the right direction [1]. Life expectancy at birth did not significantly vary from the Neolithic ( $\approx 20$ years) to Rome (between 20 and 30 years), to medieval Britain $\left(\approx 30\right.$ years) and even to early $20^{\text {th }}$ century Britain $(\approx 31$ years). Improved sanitary conditions, disease prevention (e.g., vaccinations) and treatment (e.g., antibiotics) have significantly increased life expectancy, up to the 67.2 years value in 2010 [2]. Thus, the average lifespan is steadily increasing.

Alzheimer's Disease International (ADI) estimates in its 2013 report [3] that there are more than 35 million people with dementia worldwide as of 2010, that the number will double by 2030 and triplicate to 115 million by 2050 . Numbers further increase when one takes into account all neurodegenerative diseases (NDDs).

Treatment strategies for NDDs are inadequate. Limited benefits come from compensation for neuronal loss by increasing levels of corresponding neurotransmitters in the central nervous system (CNS), without directly slowing or halting neurodegeneration. Such symptomatic therapies offer temporary relief, but the ultimate NDD outcome does not change. Is it good that our life expectancy steadily increases, if existing treatments for NDD/ageing diseases only treat the symptoms, rather than addressing the cause and eradicating, or at least halting disease progression?

Pharmaceutical research and development $(\mathrm{R} \& \mathrm{D})$ dealing with CNS, and in particular with NDDs is extremely risky and expensive. There's no question about that, but other costs should also be considered to fully evaluate the financials of NDDs. ADI estimates that for 2010 the global cost of neurodegeneration, including medical costs and 
cost of formal (e.g., nursing homes and skilled nurses) and informal (e.g., relatives) care, exceeds $\$ 600$ billion (about $1 \%$ of world gross domestic product), with disproportionatetly high costs in wealthy countries [4]. The cost of providing care for AD patients in the US is $\approx \$ 200$ billion per year in 2012 , projected to grow to $\$ 1.1$ trillion per year by 2050 [5]. A detailed analysis [6] considers the global cost of socalled "diseases of the brain" in Europe at $€ 798$ billion in $2010(37 \%$ direct healthcare costs, $23 \%$ direct non-medical costs, $40 \%$ indirect costs associated with patients' production losses). Isn't the conservative figure of $\approx \$ 2$ trillion - what we should spend in 2050 in global care for NDD patients - enough to stimulate public funding agencies and the public opinion to steadily invest in $\mathrm{R} \& \mathrm{D}$ ?

\subsection{Molecular Mechanisms}

NDDs are a heterogenic set of diseases, and multiple therapeutic intervention strategies can be conceived. Disease-modifying pathways, that should prove beneficial in the treatment of several NDDs, include oxidative [7] and nitrosative [8] stress, endoplasmic reticulum (ER) stress [9], mitochondrial injuries [10], impaired protein degradation [11], chaperone mis-functioning [12], inflammatory responses [13] and heavy metal accumulation in the brain [14].

Aggregation-prone neuronal proteins are the core of NDDs. The same protein aggregate may determine the insurgence of many NDDs. Conversely, a single NDD may entail the simultaneous presence of more than one protein aggregate. For example, extra-cellular senile plaques (SPs) in the AD brain consist of $\beta$-amyloid/A $\beta$ [15], a family of amyloidogenic peptides resulting from the cleavage by $\beta$ - and $\gamma$-secretase of the amyloid precursor protein (APP) [16]. Intra-cytoplasmic protein inclusions in familial and sporadic $\mathrm{PD}$, in dementia with Lewy bodies (DLB) and in multiple system atrophy (MSA) contain $\alpha$-synuclein [17], an aggregation-prone small protein found predominantly in neuronal tissue. Intra-neuronal protein inclusions in nine polyglutamine repeat (polyQ) diseases [18], such as HD, contain polyQ-containing proteins such as polyQ-buntingtin [19]. Therapeutically relevant aggregation-prone proteins/NDD couples also include superoxide dismutase-1 (SOD-1 [20])/amyotrophic lateral sclerosis (ALS); TAR DNAbinding protein 43 (TDP-43 [21])/ALS; fused in sarcoma (FUS [22])/ALS; and the prion protein ( $\operatorname{Pr} P,[23]) /$ prion disease. A thorough 
description of disease-modifying approaches targeted against $>600$ known NDDs, and consequently focused onto the physio-pathological features of these aggregation-prone neuronal proteins, would largely exceed the length of any review. We rather focus on the protein tau and on a set of NDDs named tauopathies.

\section{TAU AND TAUOPathiES}

\subsection{Tau: Main Features}

Tau is a highly soluble microtubule-associated protein (MAP) discovered in 1975 [24] that promotes microtubule (MT) assembly. Tau is mostly expressed in neurons in general, and axons in particular, ensuring their structural integrity [25]. The almost total absence of secondary and tertiary structural elements in tau makes it an intrinsically disordered protein (IDP) [12]. The switch of IDPs between folding states dynamically regulates their interaction with multiple partners through high specificity/low affinity interactions, and modulates many cellular processes and signalling pathways [26]. As to tau, tau-MT bindingunbinding events control the stabilization or destabilization of MT segments to regulate neuritic growth and promote axonal transport [27].

Protein aggregation [28] is influenced by a number of physicochemical and biological factors in humans. The transition from a soluble, functional protein to mis-folded, aggregation-prone species, and eventually to ordered or disordered aggregates, is promoted by proteindependent (structural features, genetic or post-traslational modifications/PTMs) and protein-independent factors (cellular, environmental stimuli) [29]. As to structural features, IDPs sample a larger conformational space, including several metastable, aggregation-prone conformations. Proteinopathy-prone IDPs include A $\beta$ [30], $\alpha$-synuclein [12] and tau [31]. As to genetic modifications, point mutations may significantly increase the aggregation tendency of a protein (i.e. the P301L mutation in tau [32]). As to PTMs, they cause aggregation and proteinopathies by influencing, inter alia, the solubility and the conformational stability of proteins (i.e the hyper-phosphorylation (HP) of tau [33]). The aging process is the most common cause of protein aggregation [34], so much that the latter is a diagnostic marker for the former process in living organisms [35]. Aging-dependent protein aggregation 
is a slow, continuous process determined by subtle chronic changes in cellular components, that impact on pathology-unrelated and -related proteins.

The single copy human tau gene MAPT, composed by 16 exons, is located on chromosome 17 [36]. Alternative splicing produces up to 30 tau isoforms [37], six of which are expressed in CNS (Fig. 1). The longer human brain tau isoform (2N4R, 441 aminoacids-AAs) contains a basic C-terminal domain (AAs 244-441), including four MT-binding repeats (MTBRs); a basic middle domain (AAs 151-243), containing two proline-rich regions (PR), and an N-terminal domain (AAs 1-150).

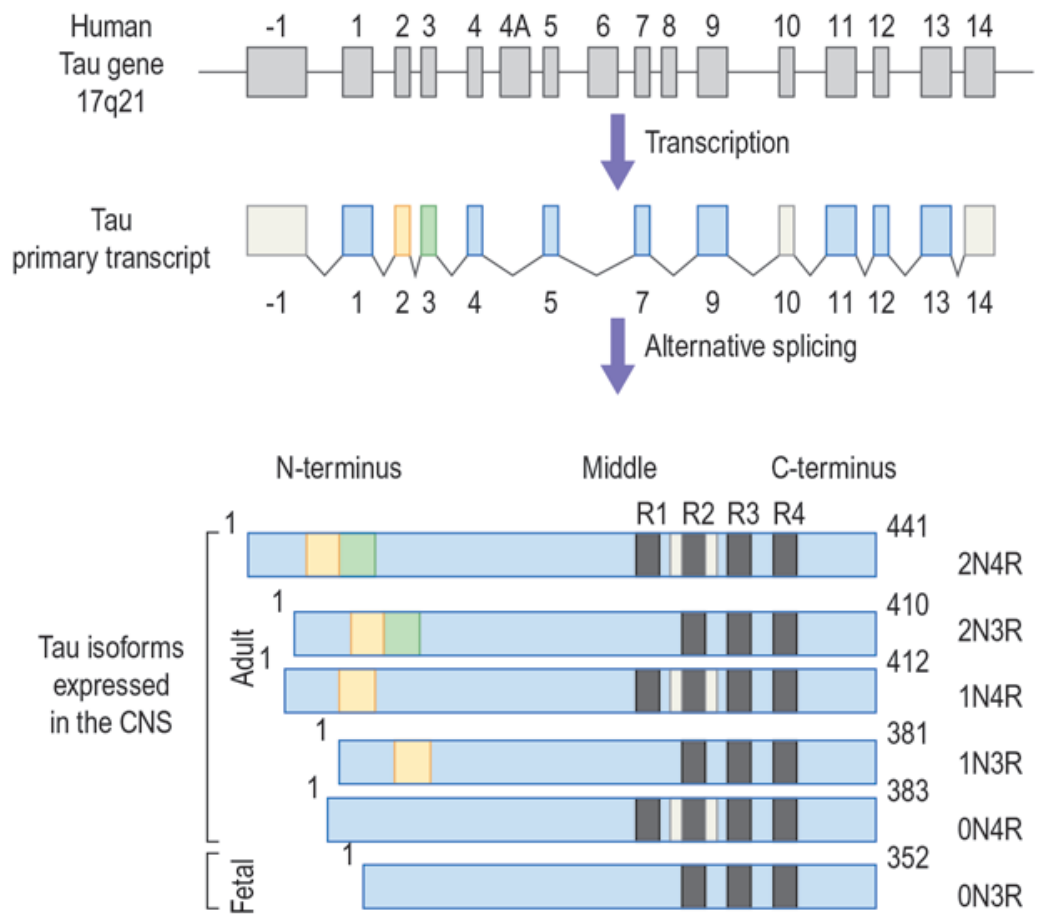

Fig. 1.

Tau isoforms result from alternative splicing of exons 2, 3 (N-terminal domain, 29 AAs in each domain, isoforms $2 \mathrm{~N}, 1 \mathrm{~N}$ and $0 \mathrm{~N}$ ) and 10 (C-terminal domain, $31 \mathrm{AAs}$, isoforms $4 \mathrm{R}$ and $3 \mathrm{R}$ ). Six CNS isoforms are observed because exon 3 is expressed only in presence of exon 2 [38]. Mutations in MAPT, resulting in familial tauopathies, are 
known. Missense mutations cause aminoacid variations in tau, while silent mutations switch the physiological 4R:3R isoform ratio [39]. Exon 10 contains an MTBR, so that 4R isoforms show stronger binding to MTs than $3 \mathrm{R}$ isoforms. Adult tau shows a $\approx 1: 14 \mathrm{R}: 3 \mathrm{R}$ ratio, a compromise between strong MT cohesion to secure neuronal integrity, and morphological plasticity needed by dynamic MT-tau complexes. An abnormal 4R:3R ratio in adult tau pools is invariably associated with MT dysfunctions and tau protein aggregation [40].

As it happens for other amyloidogenic proteins, insoluble tau aggregates/neurofibrillary tangles (NFTs) were long believed to be the major determinants of neurotoxic effects in tauopathies [41]. Now it is accepted that, while NFTs are presumably involved in tau toxicity, they may even represent an endogenous rescuing mechanism to eliminate neurotoxic, soluble oligomeric species from the neuronal environment [42].

Conversely, soluble tau oligomers are neurotoxic in a number of preclinical environments $[43,44]$, are found in the extra-cellular space [45], and propagate from cell to cell in cellular [46] and in vivo models [47]. Neurotoxic tau oligomers are observed in patients suffering from $\mathrm{AD}[48,49]$ or frontotemporal dementia and parkinsonism linked to chromosome 17 (FTDP-17) [50]. They are observed at high concentrations in the frontal cortex of early $\mathrm{AD}$ patients (Braak stage 1) before NFT formation, suggesting usefulness as pre-symptomatic diagnostics [51].

\subsection{Tauopathies: Biochemical and Clinical Description}

Each NDD showing intracellular accumulation of filamentous tau inclusions into NFTs, and disease-dependent brain dysfunctions, is defined as a tauopathy [52,53]. The identification of at least fifty-seven tau mutations on chromosome 17 in patients affected by frontotemporal dementia and parkinsonism linked to chromosome 17 (FTDP-17) [54] proves that dysfunctions in tau cause tauopathies/NDDs without any other neuropathological factor.

At least 27 tauopathies (Tab. 1) are known, including largely diffuse and extremely rare NDDs. Tau aggregates are either the only neuronal abnormality, or one of the main disease factors, or secondary inclusions associated with other main pathologies. Tauopathies are divided in familial and sporadic NDDs, and in five classes depending on the neuropathological observation of tauopathy-specific tau aggregates [55]. 
Tab. 1. - List of characterized tauopatbies.

\begin{tabular}{lccc}
\hline Tauopathy & Inclusions & \multicolumn{2}{c}{ Origin $^{\mathrm{d}}$ Class } \\
\hline AD & Main/A $\beta$ & $\mathrm{S}, \mathrm{F}^{\mathrm{d}}$ & $\mathrm{I}$ \\
\hline $\begin{array}{l}\text { Amyotrophic lateral sclerosis/parkinsonism- } \\
\text { dementia complex of Guam (ALS/PDC) }\end{array}$ & Main/TDP-43 & $\mathrm{S}$ & $\mathrm{I}$ \\
\hline Argyrophilic grain disease (AGD) & Tau only & $\mathrm{S}$ & $\mathrm{II}$ \\
\hline Corticobasal degeneration (CBD) & Tau only & $\mathrm{S}, \mathrm{F}$ & $\mathrm{II}$ \\
\hline $\begin{array}{l}\text { Dementia pugilistica/Chronic traumatic } \\
\text { encephalopathy (CTE) }\end{array}$ & Main/TDP-43, A $\beta$ & $\mathrm{S}$ & $\mathrm{I}$ \\
\hline $\begin{array}{l}\text { Diffuse neurofibrillary tangles with } \\
\text { calcification (DNTC) }\end{array}$ & Main/TDP-43, & $\mathrm{S}$ & $\mathrm{I}$ \\
\hline Down's syndrome (DS) & Main/As $\beta^{\mathrm{a}}$ & $\mathrm{S}$ & $\mathrm{I}$ \\
\hline Familial British dementia (FBD) & Main/A $\beta$-like, TDP-43 & $\mathrm{F}^{\mathrm{e}}$ & $\mathrm{I}$ \\
\hline Familial Danish dementia (FDD) & Main/A $\beta-l i k e$ & $\mathrm{~F}^{\mathrm{e}}$ & $\mathrm{I}$ \\
\hline Frontal lobe dementia, non-AD non-Pick & Lack of tau & $\mathrm{S}$ & 0 \\
\hline $\begin{array}{l}\text { Frontotemporal dementia and parkinsonism } \\
\text { linked to chromosome 17 caused by MAPT } \\
\text { mutations }\end{array}$ & Main/TDP-43, FUS & $\mathrm{F}$ & $\mathrm{I}, \mathrm{II}, \mathrm{III}$ \\
\hline
\end{tabular}

Frontotemporal lobar degeneration caused $\quad$ Support $^{\mathrm{c}} / \mathrm{TDP}-43, \quad \mathrm{~F}^{\mathrm{e}} \quad \mathrm{I}$ by C9ORF72 mutations (FTLD-C9) p62

\begin{tabular}{lcll}
\hline Gerstmann-Sträussler-Scheinker disease (GSS) & Support ${ }^{\mathrm{c}} / \mathrm{prion}$ & $\mathrm{S}$ & $\mathrm{I}$ \\
\hline Globular glial tauopathies (GGT)/White matter & Tau only & S & II
\end{tabular}
tauopathy with globular glial inclusions

\begin{tabular}{llll}
\hline $\begin{array}{l}\text { Guadeloupean parkinsonism with dementia } \\
\text { (Gd-PDC) }\end{array}$ & Tau only & S & I
\end{tabular}

\begin{tabular}{|c|c|c|c|}
\hline Guadeloupean PSP & Tau only & $\mathrm{S}$ & II \\
\hline Multiple system atrophy (MSA) & Support ${ }^{\mathrm{C}} / \alpha$-syn & $\mathrm{S}$ & $\mathrm{I}$ \\
\hline Myotonic dystrophy (DM) & Tau only ${ }^{\mathrm{a}}$ & $\mathrm{F}^{\mathrm{e}}$ & IV \\
\hline $\begin{array}{l}\text { Neurodegeneration with brain iron } \\
\text { accumulation (NBIA)/Hallevorden-Spatz } \\
\text { disease/Pantothenate kinase-associated } \\
\text { neurodegeneration (PKAN) }\end{array}$ & $\begin{array}{c}\text { Supportc/TDP-43, } \\
\alpha \text {-syn }\end{array}$ & $\mathrm{Fe}^{\mathrm{e}}$ & $\mathrm{I}$ \\
\hline
\end{tabular}

\begin{tabular}{lccc}
\hline $\begin{array}{l}\text { Neurofibrillary tangle-predominant dementia } \\
\text { (NFTPD) }\end{array}$ & Tau only & $\mathrm{S}$ & $\mathrm{I}$ \\
\hline Niemann-Pick disease, type C (NPC) & Tau only ${ }^{\mathrm{a}}$ & $\mathrm{Fe}^{\mathrm{e}}$ & $\mathrm{I}$ \\
\hline Pick's disease (PiD) & Tau only & $\mathrm{S}$ & $\mathrm{III}$ \\
\hline Postencephalitic parkinsonism (PEP) & Main/A $\beta$ & $\mathrm{S}$ & $\mathrm{I}$ \\
\hline $\begin{array}{l}\text { Prion protein cerebral amyloid angiopathy } \\
\text { (PrPCAA) }\end{array}$ & Support $/$ prion & $\mathrm{Fe}^{\mathrm{e}}$ & $\mathrm{I}$ \\
\hline Progressive supranuclear palsy (PSP) & Tau only & $\mathrm{S}$ & $\mathrm{II}$ \\
\hline SLC9A6-related mental retardation & Tau only ${ }^{\mathrm{a}}$ & $\mathrm{S}$ & $\mathrm{II}$ \\
\hline Subacute sclerosing panencephalitis (SSPE) & Tau only & $\mathrm{S}$ & $\mathrm{I}$ \\
\hline
\end{tabular}

${ }^{a}$, the main disease cause is not the proteinopathy/tauopathy; ${ }^{b}$, each pathology is typical of FTDP17 sub-classes, no overlapping proteinopathies; ' , tau pathology has lesser importance than the other proteinopathies; ${ }^{\mathrm{d}}, \mathrm{S}=$ sporadic, $\mathrm{F}=$ familial; ${ }^{\mathrm{e}}$, other proteins than tau are mutated. 
A single class 0 tauopatby is characterized by a lack of neuropathological hallmarks of tau [55]. Class I tauopatbies (eighteen) are defined by the presence in insoluble HP tau aggregates of three major tau bands at 60, 64 and $69 \mathrm{kDa}$, and of a less intense band at 72-74 $\mathrm{kDa}$ [55]. The $60 \mathrm{kDa}$ band corresponds to the $0 \mathrm{~N} 3 \mathrm{R}$ isoform; the 64 $\mathrm{kDa}$ band corresponds to the $1 \mathrm{~N} 3 \mathrm{R}$ and $0 \mathrm{~N} 4 \mathrm{R}$ isoforms; the $69 \mathrm{kDa}$ band corresponds to the $2 \mathrm{~N} 3 \mathrm{R}$ and $1 \mathrm{~N} 4 \mathrm{R}$ isoforms; and the $72-74$ $\mathrm{kDa}$ band corresponds to the longest 2N4R tau isoform. Class II tauopatbies (seven) are defined by the presence in insoluble HP tau aggregates of two major tau bands at 64 and $69 \mathrm{kDa}$, and of a less intense band at $72-74 \mathrm{kDa}$ [55]. This profile corresponds to aggregates composed in large part by $4 \mathrm{R}$ tau isoforms, as class II tau aggregates are heavily stained by exon 10-specific antibodies [53]. A single class III tauopatby is defined by the presence in insoluble HP tau aggregates of two major tau bands at 60 and $64 \mathrm{kDa}$, and of a less intense band at $69 \mathrm{kDa}$ [55]. This corresponds to aggregates composed in large part by $3 \mathrm{R}$ tau isoforms, as class II tau aggregates do not stain in presence of exon 10-specific antibodies. A single class IV tauopatby is defined by the presence in insoluble HP tau aggregates of a single major tau band at $60 \mathrm{kDa}$, and of two less intense bands at 64 and $69 \mathrm{kDa}$ [55]. This profile corresponds to aggregates composed in large part by the smallest tau isoform 0N3R [53].

\section{Tau and Post-Translational Modifications (PTMs)}

The basic-polar nature of tau supports its interaction with acidic MTs, and favors PTMs on tau [56,57]. PTM patterns, and phosphorylation in particular, heavily influence the conformational stability, the interaction network, and the physico-chemical properties (including aggregation propensity) of tau [56].

\subsection{Phosphorylation: Kinases, Phosphatases, GSK-3 $\beta$}

Phosphorylation of tau has a strong impact on its functions [58]. Out of 85 Ser, Thr and Tyr residues, more than 30 are mostly phosphorylated in non-diseased brains, around 15 in both physiological and pathological conditions, and almost 30 are phosphorylated in AD brains [56]. Tau varies its phosphorylation state depending on its local- 
ization [59] and on developmental stage, as fetal human tau is more phosphorylated than adult tau [60]. Adult HP tau is a marker for tau aggregation, and a risk factor for tauopathies [61]. HP fetal tau is highly soluble and perfectly functional [62].The HP pattern in human brain tissues from AD patients is different from human fetal tau. Namely, residues S202, T212, S214, T217, T231, S262, S396, S404 and S422 are linked to adult HP [63] as early, intermediate or late stage, tauopathyspecific hyper-phosphorylated epitopes $[64,65]$.

An updated, online-available Table [66] provides the phosphorylation specificity for 33 putative tau kinases. In pathological conditions some of them may increase their activity on tau, and/or that the activity of their phosphatase counterparts is reduced. Targeting a decrease of tau $H P$ is an assessed drug discovery approach against tauopathies, as several tau kinase inhibitors have entered clinical trials [67].

In particular, glycogen synthase kinase 3 beta (GSK-3 $\beta$ [68] phosphorylates in vitro up to $40 \mathrm{Ser}$ and Thr residues [69], and is, together with CK1, the most efficient kinase in phosphorylating tau. All but one of phosphorylated residues found in control human brains, and the majority (27 out of 45) of tauopathy-specific, HP epitopes of tau found in brains from $\mathrm{AD}$ patients are phosphorylated in vitro by GSK-3 $\beta$ [70]. Treatment of cultured cortical neurons with small molecule GSK$3 \beta$ inhibitors in a model of tau hyper-phosphorylation induced by okadaic acid (OA, a protein phosphatase $2 \mathrm{~A}$ inhibitor) [71] reverse the OA-induced pathological tau pattern without any toxicity, i.e., without inhibition of essential, physiological tau phosphorylation [71]. GSK-3 $\beta$ also phosphorylates the Thr668 residue on the amyloid precursor protein (APP), hinting to a potential role for GSK-3 $\beta$ inhibitors as neuroprotective-A $\beta$ anti-aggregant agents [72]. In vivo validation of GSK-3 $\beta$ as a tauopathy- $\mathrm{AD}$ target is copious [73]. Transgenic mice bearing conditionally expressed GSK-3 $\beta$ as such [74], or crossed with tauopathiesinducing mutated tau isoforms [75], are known. They are considered suitable tauopathy models to test GSK-3 $\beta$ inhibitors.

GSK-3 $\beta$ is considered a valuable therapeutic target since early ' 80 s, and a steady flow of patents and papers dealing with hundreds of compound classes as GSK-3 $\beta$ inhibitors started in the last decade [76], and were recently reviewed $[77,78]$.

Fig. 2 depicts the impact of phosphorylation and of other PTMs on the dynamic equilibrium between native tau (folded, soluble species) and HP tau (aggregation-prone species). Pro-aggregation 
PTMs acting on HP-tau and promoting the formation of insoluble tau aggregates are also shown.

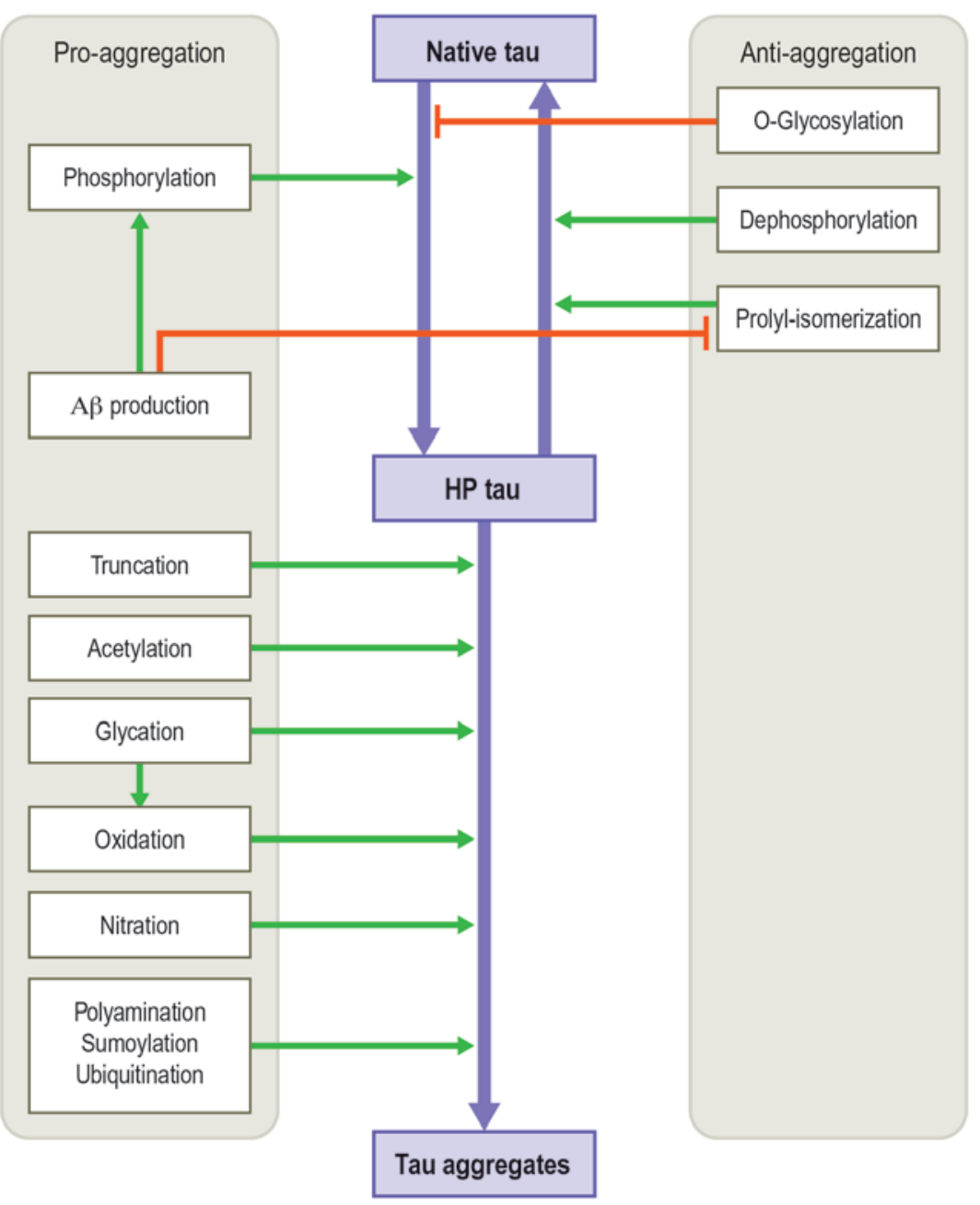

Fig. 2.

\subsection{O-GlcNAcylation: Transferases, Hydrolases, OGA}

O-glycosylation with $\mathrm{N}$-acetylglucosamine (O-GlcNAcylation) is essential for the regulation of proteins in physiological and pathological 
states [79]. O-GlcNAcylation negatively regulates tau phosphorylation [80], prevents tau aggregation and the risk for tauopathies. A decreased level of tau O-GlcNAcylation is observed in brains from AD patients, as is correlation between tau hypo-GlcNAcylation and HP [81]. Thus, an increase of O-GlcNAcylation on tau is a sound therapeutic goal.

OGT [82], an O-GlcNAc transferase, introduces an $\mathrm{N}$-acetylglucosamine moiety on up to $11 \mathrm{Ser}$ and Thr residues of tau, and on more than 500 other protein substrates. OGA [83], an O-GlcNAc hydrolase, removes GlcNAc from the same residues/substrates in a dynamic equilibrium. Several papers $[84,85]$ review the mechanism of action, the substrate specificity and the main properties of OGT and OGA. Either an increase of OGT activity, or a decrease of OGA activity could lead to an increase of tau O-GlcNAcylation. The latter is a more achievable goal, as structure-based drug design of enzyme inhibitors is well documented in literature [86]. Thus, OGA has become the target of drug discovery projects.

Most known OGA inhibitors are OGlcNAc mimics, as elucidation of the substrate-assisted enzymatic mechanism [87] of OGA permits their rational design-structural optimization-fine tuning. The availability of X-ray structures of human OGA homologues complexed with inhibitors $[88,89]$ provides inspiration for the rational drug design of OGA-targeted inhibitors with selectivity against structurally related hydrolases [83,90], as recently reviewed [91]. In vitro [92] and in vivo [93] data using a selective OGA inhibitor did not alter glucose homeostasis, and hinted to a cleaner activity profile for such molecules. Thus, the rationale for OGA inhibitors as PTM-correcting agents in neurodegeneration is strong.

\subsection{Peptidyl-Prolyl Isomerization: Isomerases, Phosphatases, Pin1}

Cis and trans conformations of the X-Pro amide bond strongly influence the folding of Pro-rich protein regions [94]. Peptidyl prolyl isomerization of one or more X-Pro amides in a protein may influence the accessibility of a domain to PTM enzymes, with functional consequences [95]. The middle region of tau contains two Pro-rich domains and 21 Pro residues. The inhibition of X-Pro amide bond isomerization on the pT231-P232 epitope is a pathology-related event which appears in the early phases of tau pathologies [96]. The phosphorylated epitope causes major conformational changes in tau, leading to the phosphory- 
lation of other pathological epitopes [97]. Its use as a diagnostic tool to observe the progression of AD in cerebrospinal fluid (CSF) is suggested, due to a direct correlation between increased CSF levels and AD severity [98]. Thus, $p$ Thr-Pro cis-trans isomerization of tau is a meaningful target against tauopathies.

The parvulin PPIase Pin1 (peptidyl-prolyl cis/trans isomerase NIMA interacting-1) [99] has specific PPIase activity on more than 50 protein sequences containing the pSer/pThr-Pro phosphorylated dipeptide [100]. It regulates key cellular events involved in physiological [101] and pathological processes [102]. Tau is the first Pin1 substrate identified in neurons [103]. Pin1 targets-isomerizes the cis pT231-P232 amide bond on tau, promoting its dephosphorylation catalyzed by trans-specific phosphatase PP2A [104].

A Pin1-centered intervention in tauopathies should restore its functions in diseased brain areas. Small molecule Pin1 enhancers are not yet reported, and can not be easily conceived. Pin1 modulators, i.e. small molecules acting on Pin1 regulators, could provide the same result. A more druggable set of targets relies on PTMs of Pin1, and in particular on the phosphorylation of two negative regulatory epitopes Ser16 and Ser71 - respectively by polo-like-kinase-1 (PLK1) [105] and death-associated protein kinase 1 (DAPK1) [106].

Tau acetylation reduces the affinity of tau for MTs and has a proaggregation effect [107]. It is observed in most patients suffering by tauopathies [108], while acetylated tau is not observed in primary cultured neurons [109]. Acetylation mostly takes place on Lys274 and Lys280 residues in the MTBR [109]. The latter epitope is strongly associated to sporadic AD and other tauopathies [110].

The proteolytic cleavage of tau [111] is promoted by its IDP nature, that ensures the access of large tau regions to brain proteases [112]. Epitope-specific phosphorylation promotes tau processing [113], although inhibition of tau cleavage by phosphorylation of a specific residue is also observed [114]. Tau is cleaved in vitro by trypsin, chymotrypsin, and endogenous proteases [115]. Tissue samples from NDD patients contain tau fragments generated by caspases [116] and calpains [117]. In particular, caspases cleave tau at Asp421 in AD patients [118], producing the aggregation-prone/neurotoxic tau C fragment [119].

Tau glycation [120], nitration [121], polyamination [122], sumoylation [123] and oxidation [124] have effects on tau functions, mis-fold- 
ing and aggregation, and may in future be fully validated as diseasemodifying therapeutic options against tauopathies.

\section{CONCLUSIONS}

The prevention-remediation of tbiochemical alterations of tau is a therapeutically relevant target against tauopathies. While the restoration of physiological PTM tau profiles is an assessed route, new ones aim to refold tau and prevent its aggregation (chaperone intervention [125]), or to dispose of misfolded soluble oligomers and insoluble aggregates of tau (ubiquitin-proteasome degradation [126], autophagy [127], aggrephagy [128]). Although still largely unclarified, it is reasonable to assume that they will in some years generate a flow of clinical candidates against tauopathies.

\section{BIBLIOGRAPHY}

[1] http://en.wikipedia.org/wiki/Life_expectancy

[2] https://www.cia.gov/library/publications/the-world-factbook/rankorder/2102 rank.html

[3] http://www.alz.co.uk/research/WorldAlzheimerReport2013ExecutiveSummary. pdf

[4] http://www.alz.co.uk/research/world-report

[5] http://www.alz.org/downloads/facts_figures_2012.pdf

[6] Gustavsson A., Svensson M., Jacobi F., et al. Cost of disorders of the brain in Europe 2010. Eur. Neuropsychopharmacol., 2011, 21, 718-79.

[7] Oxidative Stress and Neurodegenerative Disorders. Qureshi G.A., Parvez S.H., Eds. Elsevier, Amsterdam, The Netherlands, 2007.

[8] Pacher P., Beckman J.S., Liaudet L. Nitric oxide and peroxynitrite in health and disease. Physiol. Rev., 2007, 87, 315-424.

[9] Salminen A., Kauppinen A., Suuronen T., Kaarniranta K., Ojala J. ER stress in Alzheimer's disease: a novel neuronal trigger for inflammation and Alzheimer's pathology. J. Neuroinflamm., 2009, 6, 41.

[10] Moreira P.I., Zhu X., Wang X., et al. Mitochondria: a therapeutic target in neurodegeneration. Biochim. Biophys. Acta, 2010, 1802, 212-220.

[11] Matsuda N., Tanaka K. Does impairment of the ubiquitin-proteasome system or the autophagy-lysosome pathway predispose individuals to neurodegenerative disorders such as Parkinson's disease? J. Alzheimers Dis., 2010, 19:1-9.

[12] Uversky V.N. Flexible nets of malleable guardians: Intrinsically disordered chaperones in neurodegenerative diseases. Chem. Rev., 2011, 111, 1134-1166. 
[13] Amor S., Puentes F., Baker D., Van Der Valk P. Inflammation in neurodegenerative diseases. Immunology, 2010, 129, 154-169.

[14] Bush A.I. Metals and neuroscience. Curr. Opin. Chem. Biol., 2000, 4, 184-191.

[15] Hardy J., Selkoe D.J. The amyloid hypothesis of Alzheimer's disease: progress and problems on the road to therapeutics. Science, 2002, 297, 353-356.

[16] Haass C., De Strooper B. The presenilins in Alzheimer's disease-proteolysis holds the key. Science, 1999, 286, 916-919.

[17] Goedert M. $\alpha$-synuclein and neurodegenerative diseases. Nat. Rev. Neurosci., 2001, 2, 492-501.

[18] Zoghbi H.Y., Orr H.T. Glutamine repeats and neurodegeneration. Annu. Rev. Neurosci., 2000, 23, 217-247.

[19] Young A.B. Huntingtin in health and disease. J. Clin. Invest., 2003, 111, 299-302.

[20] Rosen D.R., Siddique T., Patterson D., et al. Mutations in Cu/Zn superoxide dismutase gene are associated with familial amyotrophic lateral sclerosis. Nature, 1993, 362, 59-62.

[21] Neumann M., Sampathu D.M., Kwong L.K., et al. Ubiquitinated TDP-43 in frontotemporal lobar degeneration and amyotrophic lateral sclerosis. Science, 2006, 314, 130-133.

[22] Kwiatkowski T.J. Jr., Bosco D.A., Leclerc A.L., et al. Mutations in the FUS/TLS gene on chromosome 16 cause familial amyotrophic lateral sclerosis. Science, 2009, 323, 1205-1208.

[23] Prusiner S.B., Scott M.R., DeArmond S.J., Cohen F.E. Prion protein biology. Cell, 1998, 93, 337-348.

[24] Weingarten M.D., Lockwood A.H., Hwo S.Y., Kirschner M.W. A protein factor essential for microtubule assembly. Proc. Natl. Acad. Sci. U.S.A., 1975, 72, 1858 1862.

[25] Hirokawa N. Microtubule organization and dynamics dependent on microtubule-associated proteins. Curr. Opin. Cell Biol., 1994, 6, 74-81.

[26] Dyson H.J., Wright P.E. Intrinsically unstructured proteins and their functions. Nat. Rev. Mol. Cell Biol., 2005, 6, 197-208.

[27] Zheng S., Chen Y., Donahue C.P., Wolfe M.S., Varani G. Structural basis for stabilization of the tau pre-mRNA splicing regulatory element by novantrone (mitoxantrone). Chem. Biol., 2009, 16, 557-566.

[28] Chiti F., Dobson C.M. Protein misfolding, functional amyloid, and human disease. Annu. Rev. Biochem., 2006, 75, 333-366.

[29] Uversky V.N. Mysterious oligomerization of the amyloidogenic proteins. FEBS J., 2010, 277, 2940-2953.

[30] Rosenman D.J., Connors C.R., Chen W., Wang C., García A.E. A $\beta$ monomers transiently sample oligomer and fibril-like configurations: Ensemble characterization using a combined MD/NMR approach. J. Mol. Biol., 2013, 425, 33383359.

[31] Elbaum-Garfinkle S., Rhoades E. Identification of an aggregation-prone structure of tau. J. Am. Chem. Soc., 2012, 134, 16607-16613.

[32] Terwel D., Lasrado R., Snauwaert J., et al. Changed conformation of mutant tau- 
P301L underlies the moribund tauopathy, absent in progressive, nonlethal axonopathy of tau-4R/2N transgenic mice. J. Biol. Chem., 2005, 280, 3963-3973.

[33] Vassar R., Bennett B.D., Babu-Khan S., et al. $\beta$ - Secretase cleavage of Alzheimer's amyloid precursor protein by the transmembrane aspartic protease BACE. Science, 1999, 286, 735-741.

[34] David D.C. Aging and the aggregating proteome. Front. Genet., 2012, 3, 347.

[35] David D.C., Ollikainen N., Trinidad J.C., et al. Widespread protein aggregation as an inherent part of aging in C. elegans. PLoS Biol., 2010, e1000450.

[36] Neve R.L., Harris P., Kosik K.S., Kurnit D.M., Donlon T.A. Identification of cDNA clones for the human microtubule-associated protein tau and chromosomal localization of the genes for tau and microtubule-associated protein 2. Brain Res., 1986, 387, 271-280.

[37] Andreadis A. Tau gene alternative splicing: Expression pattern, regulation and modulation of function in normal brain and neurodegenerative disease. Biochem. Biophys. Acta, 2005, 1739, 91-103.

[38] Andreadis A., Brown W.M., Kosik K.S. Structure and novel exons of the human T gene. Biochemistry, 1992, 31, 10626-10633.

[39] Goedert M., Spillantini M.G. Pathogenesis of the tauopathies. J. Mol. Neurosci., 2011, 45, 425-431.

[40] Crespo-Biel N., Theunis C., Van Leuven F. Protein tau: Prime cause of synaptic and neuronal degeneration in Alzheimer's disease. Int. J. Alzheim. Dis., 2012, 251426.

[41] Arriagada P.V., Growdon J.H., Hedley-Whyte E.T., Hyman B.T. Neurofibrillary tangles but not senile plaques parallel duration and severity of Alzheimer's disease. Neurology, 1992, 42, 631-639.

[42] Spires-Jones T.L., Kopeikina K.J., Koffie R.M., de Calignon A., Hyman B.T. Are tangles as toxic as they look? J. Mol. Neurosci., 2011, 45, 438-444.

[43] Berger Z., Roder H., Hanna A., et al. Accumulation of pathological tau species and memory loss in a conditional model of tauopathy. J. Neurosci., 2007, 27, 3650-3662.

[44] Wittmann C.W., Wszolek M.F., Shulman J.M., et al. Tauopathy in drosophila: neurodegeneration without neurofibrillary tangles. Science, 2001, 293, 711-714.

[45] Lasagna-Reeves C.A., Castillo-Carranza D.L., Sengupta U., et al. Identification of oligomers at early stages of tau aggregation in Alzheimer's disease. FASEB J., 2012, 26, 1946-1959.

[46] Michel C.H., Kumar S., Pinotsi D., et al. Extracellular monomeric tau protein is sufficient to initiate the spread of tau protein pathology. J. Biol. Chem., 2014, 289, 956-967.

[47] de Calignon A., Polydoro M., Suárez-Calvet M., et al. Propagation of tau pathology in a model of early Alzheimer's disease. Neuron, 2012, 73, 685-697.

[48] Ladiwala A.R.A., Dordick J.S., Tessier P.M. Aromatic small molecules remodel toxic soluble oligomers of amyloid $\beta$ through three independent pathways. $J$. Biol. Chem., 2011, 286, 3209-3218.

[49] Mori T., Rezai-Zadeh K., Koyama N., et al. Tannic acid is a natural $\beta$-secretase 
inhibitor that prevents cognitive impairment and mitigates Alzheimer-like pathology in transgenic mice. J. Biol. Chem., 2012, 287, 6912-6927.

[50] Chang E., Congdon E.E., Honson N.S., Duff K.E., Kuret J. Structure-activity relationship of cyanine tau aggregation inhibitors. J. Med. Chem., 2009, 52, 3539-3547.

[51] Song J.M., DiBattista A.M., Sung Y.M., et al. A tetra(ethylene glycol) derivative of benzothiazole aniline ameliorates dendritic spine density and cognitive function in a mouse model of Alzheimer's disease. Exp. Neurol., 2014, 252, 105-113.

[52] Buee L., Bussie T., Buee-Scherrerb V., Delacourte A., Hof P.R. Tau protein isoforms, phosphorylation and role in neurodegenerative disorders. Brain Res. Rev., 2000, 33, 95-130.

[53] Lee V.M.-J., Goedert M., Trojanowski J.Q. Neurodegenerative tauopathies. Annu. Rev. Neurosci., 2001, 24, 1121-1159.

[54] Spillantini M.G., Goedert M. Tau pathology and neurodegeneration. Lancet Neurol., 2013, 12, 609-622.

[55] Sergeant N., Delacourte A., Buee L. Tau protein as a differential biomarker of tauopathies. Biochim. Biophys. Acta, 2005, 1739, 179-197.

[56] Martin L., Latypova X., Terro F. Post-translational modifications of tau protein: Implications for Alzheimer's disease. Neurochem. Int., 2011, 58, 458-471.

[57] Perry G., Zhu X., Smith M.A., Sorensen A., Avila J., Wang J.-Z., Xia Y.-Y., Grundke-Iqbal I., Iqbal K. Abnormal hyperphosphorylation of tau: Sites, regulation, and molecular mechanism of neurofibrillary degeneration. J. Alzheimer's Dis., 2013, 33, S123-S139.

[58] Lee V.M. Regulation of tau phosphorylation in Alzheimer's disease. Ann. N.Y. Acad. Sci., 1996, 777, 107-113.

[59] Riederer B.M., Binder L.I. Differential distribution of tau proteins in developing rat cerebellum. Brain Res. Bull., 1994, 33, 155-161.

[60] Brion J.-P., Octave J.N., Couck A.M. Distribution of the phosphorylated microtubule-associated protein tau in developing cortical neurons. Neuroscience, 1994, 63, 895-909.

[61] Badiola N., Suarez-Calvet M., Lleo A. Tau phosphorylation and aggregation as a therapeutic target in tauopathies. CNS Neurol. Dis. Drug Targets, 2010, 9, 727740.

[62] Hof P.R., Simic G. Human fetal tau protein isoform: Possibilities for Alzheimer's disease treatment. Int. J. Biochem. Cell Biol., 2012, 44, 1290-1294.

[63] Yu Y., Run X., Liang Z., et al. Developmental regulation of tau phosphorylation, tau kinases, and tau phosphatases. J. Neurochem., 2009, 1480-1494.

[64] Su B., Wang X., Drew K.L., et al. Physiological regulation of tau phosphorylation during hibernation. J. Neurochem., 2008, 105, 2098-2108.

[65] Bertrand J., Plouffe V., Senechal P., Leclerc N. The pattern of human tau phosphorylation is the result of priming and feedback events in primary hippocampal neurons. Neuroscience, 2010, 168, 323-334.

[66] http://cnr.iop.kcl.ac.uk/hangerlab/tautable 
[67] Savage M.J., Gingrich D.E. Advances in the development of kinase inhibitor therapeutics for Alzheimer's disease. Drug Devel. Res., 2009, 70, 125-144.

[68] Mondragon-Rodriguez S., Perry G., Zhu X., Moreira P.I., Williams S. Glycogen synthase kinase 3: a point of integration in Alzheimer's disease and a therapeutic target? Int. J. Alzheimer's Dis., 2012, 276803.

[69] Hanger D.P., Byers H.L., Wray S., et al. Novel phosphorylation sites in tau from Alzheimer brain support a role for casein kinase 1 in disease pathogenesis. J. Biol. Chem., 2007, 282, 23645-23654.

[70] Hanger D.P., Noble W. Functional implications of glycogen synthase kinase-3mediated tau phosphorylation. Int. J. Alzheim. Dis., 2011, 352805.

[71] Martin L., Page G., Terro F. Tau phosphorylation and neuronal apoptosis induced by the blockade of PP2A preferentially involve GSK-3 $\beta$. Neurochem. Int., 2011, 59, 235-250.

[72] Aplin A.E., Gibb G.M., Jacobsen J.S., Gallo J.M., Anderson B.H. In vitro phosphorylation of the cytoplasmic domain of the amyloid precursor protein by glycogen synthase kinase-3 3 . J. Neurochem., 1996, 67, 699-707.

[73] Gomes-Sintes R., Hernandez F., Lucas J.J., Avila J. GSK-3 mouse models to study neuronal apoptosis and neurodegeneration. Front. Molec. Neurosci., 2011, 4, 45 .

[74] Engel T., Hernandez F., Avila J., Lucas J.J. Full reversal of Alzheimer's diseaselike phenotype in a mouse model with conditional overexpression of glycogen synthase kinase-3. J. Neurosci., 2006, 26, 5083-5090.

[75] Terwel D., Muyllaert D., Dewachter I., et al. Amyloid activates GSK-3beta to aggravate neuronal tauopathy in bigenic mice. Am. J. Pathol, 2008, 172, 786-798.

[76] Phukan S., Babu V.S., Kannoji A., Hariharan R., Balaji V.N. GSK-3beta: role in therapeutic landscape and development of modulators. Br. J. Pharmacol., 2010, 160, 1-19.

[77] Cohen P., Goedert M. GSK3 inhibitors: Development and therapeutic potential. Nat. Rev. Drug Discov., 2004, 3, 479-487.

[78] Eldar-Finkelman H., Martinez A. GSK-3 inhibitors: preclinical and clinical focus on CNS. Front. Molec. Neurosci., 2011, 4, 32.

[79] Hanover J.A., Krause M.W., Love D.C. Bittersweet memories: Linking metabolism to epigenetics through O-GlcNacylation. Nat. Rev. Mol. Cell Biol., 2012, 13, 312-321.

[80] Lazarus B.D., Love D.C., Hanover J.A. O-GlcNAc cycling: Implications for neurodegenerative disorders. Int. J. Biochem. Cell Biol., 2009, 41, 2134-2146.

[81] Liu Y., Liu F., Grundke-Iqbal I., Iqbal K., Gong Cheng-X. Brain glucose transporters, O-GlcNAcylation and phosphorylation of tau in diabetes and Alzheimer's disease. J. Neurochem., 2009, 111, 242-249.

[82] Haltiwanger R.S., Holt G.D., Hart G.W. Enzymatic addition of O-GlcNAc to nuclear and cytoplasmic proteins. Identification of a uridine diphospho- $N$ acetylglucosamine:peptide beta- $N$-acetylglucosaminyltransferase. J. Biol. Chem., 1990, 265, 2563-2568.

[83] Comtesse N., Maldener E., Meese E. Identification of a nuclear variant of 
MGEA5, a cytoplasmic hyaluronidase and a beta- $N$-acetylglucosaminidase. Biochem. Biophys. Res. Commun., 2001, 283, 634-640.

[84] Gloster T.M., Vocadlo D.J. Mechanism, structure, and inhibition of O-GlcNAc processing enzymes. Curr. Signal Transduct, Ther., 2010, 5, 74-91.

[85] Shen D.L., Gloster T.M., Yuzwa S.A., Vocadlo D.J. Insights into O-linked NAcetylglucosamine (O-GlcNAc) processing and dynamics through kinetic analysis of OGlcNAc transferase and O-GlcNACase activity on protein substrates. J. Biol. Chem., 2012, 287, 15395-15408.

[86] Kuntz I.D. Structure-based drug design: past, present and future. Solvay Pharm. Conf., 2009, 9, 23-27.

[87] Vocadlo D.J., Davies G.J. Mechanistic insights into glycosidase chemistry. Curr. Opin. Chem. Biol., 2008, 12, 539-555.

[88] Dennis R.J., Taylor E.J., Macauley M.S., et al. Structure and mechanism of a bacterial beta-glucosaminidase having O-GlcNAcase activity. Nat. Struct. Mol. Biol., 2006, 13, 365-371.

[89] He Y., Bubb A.K., Stubbs K.A., Gloster T.M., Davies G.J. Inhibition of a bacterial O-GlcNAcase homologue by lactone and lactam derivatives: structural, kinetic and thermodynamic analyses. Amino Acids, 2011, 40, 829-839.

[90] Lameira J., Nahum Alves C., Tunon I., Marti S., Moliner V. Enzyme molecular mechanism as a starting point to design new inhibitors: a theoretical study of $\mathrm{O}$ GlcNAcase. J. Phys. Chem. B, 2011, 8, 6764-6775.

[91] Macauley M.S., Vocadlo D.J. Increasing O-GlcNAc levels: An overview of small-molecule inhibitors of O-GlcNAcase. Biochim. Biophys. Acta, 2010, 1800, 74-91.

[92] Macauley M.S., He Y., Gloster T.M., et al. Inhibition of O-GlcNAcase using a potent and cell-permeable inhibitor does not induce insulin resistance in $3 \mathrm{~T} 3$. L1 adipocytes. Chem. Biol., 2010, 17, 937-948.

[93] Macauley M.S., Shan X., Yuzwa S.A., Gloster T.M., Vocadlo D.J. Elevation of global O-GlcNAc in rodents using a selective O-GlcNAcase inhibitor does not cause insulin resistance or perturb glucohomeostasis. Chem. Biol., 2010, 17, 949-958.

[94] Wedemeyer W.J., Welker E., Scheraga H.A. Proline cis-trans isomerization and protein folding. Biochemistry, 2002, 41, 14637-14644.

[95] Zhou X.Z., Lu P.-J., Wulf G., Lu K.P. Phosphorylation-dependent prolyl isomerization. A novel signaling regulatory mechanism. Cell. Mol. Life Sci., 1999, 56, 788-806.

[96] Hampel H., Buerger K., Kohnken R., et al. Tracking of Alzheimer's disease progression with cerebrospinal fluid tau protein phosphorylated at threonine 231, Ann. Neurol., 2001, 49, 545-546.

[97] Luna-Munoz J., Chavez-Macias L., Garcia-Sierra F., Mena R. Earliest stages of tau conformational changes are related to the appearance of a sequence of specific phosphodependent tau epitopes in Alzheimer's disease. J. Alzheimer's Dis., 2007, 12, 365-375.

[98] Kohnken R., Buerger K., Zinkowski R., et al. Detection of tau phosphorylated at 
threonine 231 in cerebrospinal fluid of Alzheimer's disease patients. Neurosci. Lett., 2000, 287, 187-190.

[99] Lu K.P., Hanes S.D., Hunter T. A human peptidylprolyl isomerase essential for regulation of mitosis. Nature, 1996, 380, 544-547.

[100] Lu K.P., Zhou X.-Z. The prolyl isomerase PIN1: a pivotal new twist in phosphorylation signalling and disease. Nat. Rev. Mol. Cell. Biol., 2007, 8, 904-916.

[101] Pearson G., Robinson F., Beers Gibson T., et al. Mitogen-activated protein (MAP) kinase pathways: regulation and physiological functions. Endocr. Rev., 2001, 22, 153C-183C.

[102] Balastik M., Lim J., Pastorino L., Lu K.P. Pin1 in Alzheimer's disease: multiple substrates, one regulatory mechanisms? Biophys. Biochem. Acta, 2007, 1772, 422-429.

[103] Lu P.J., Wulf G., Zhou X.Z., Davies P., Lu K.P. The prolyl isomerase Pin1 restores the function of Alzheimer-associated phosphorylated tau protein. Nature, 1999, 399, 784-788.

[104] Landrieu I., Smet-Nocca C., Amniai L., et al. Molecular implication of PP2A and Pin 1 in the Alzheimer's disease specific hyperphosphorylation of tau. PLoS One, 2011, 6, e21521.

[105] Bulbarelli A., Lonati E., Cazzaniga E., Gregori M., Masserini M. Pin1 affects tau phosphorylation in response to A $\beta$ oligomers. Mol. Cell. Neurosci., 2009, 42, 75-80.

[106] Bialik S., Kimchi A. The death-associated protein kinases: structure, function, and beyond. Annu. Rev. Biochem., 2006, 75, 189-210.

[107] Min S.W., Cho S.H., Zhou Y., et al. Acetylation of tau inhibits its degradation and contributes to tauopathy. Neuron, 2010, 67, 953-966.

[108] Cohen T.J., Guo J.L., Hurtado D.E., et al. The acetylation of tau inhibits its function and promotes pathological tau aggregation. Nat. Commun., 2011, 2, 252.

[109] Cohen T.J., Friedmann D., Hwang A.W., Marmorstein R., Lee V.M.Y. The microtubule-associated tau protein has intrinsic acetyltransferase activity. Nat. Struct. Mol. Biol., 2013, 20, 756-762.

[110] Irwin D.J., Cohen T.J., Grossman M., et al. Acetylated tau, a novel pathological signature in Alzheimer's disease and other tauopathies. Brain, 2012, 135, 807-818.

[111] Hanger D.P., Wray S. Tau cleavage and tau aggregation in neurodegenerative disease. Biochem. Soc. Trans., 2010, 38, 1016-1020.

[112] Proteases in the brain. Volume 3 in "Proteases in biological diseases". 2005. Editors: Lendeckel U., Hooper N.M. Springer Science and Business Media, Inc., New York. 383 pages.

[113] Johnson G.V.W. Tau phosphorylation and proteolysis: Insights and perspectives. J. Alzheim. Dis., 2006, 9, 243-250.

[114] Guillozet-Bongaards A.L., Cahill M.E., Cryns V.L., et al. Pseudophosphorylation of tau at serine 422 inhibits caspase cleavage: in vitro evidence and implications for tangle formation. J. Neurochem., 2006, 97, 1005-1014.

[115] Wang I., Garg S., Mandelkow E.-M., Mandelkow E. Proteolytic processing of tau. Biochem. Soc. Trans., 2010, 38, 955-961. 
[116] Rohn T.T. The role of caspases in Alzheimer's disease; potential novel therapeutic opportunities. Apoptosis, 2010, 15, 1403-1409.

[117] Getz G.S. Calpain inhibition as a potential treatment of Alzheimer's disease. Am. J. Physiol., 2012, 181, 388-391.

[118] Basurto-Islas G., Luna-Munoz J., Guillozet-Bongaards A.L., et al. Accumulation of aspartic acid 421- and glutamic acid 391-cleaved tau in neurofibrillary tangles correlates with progression in Alzheimer's disease. J. Neurophathol. Exp. Neurol., 2008, 67, 470-483.

[119] Chung C.W., Song Y.H., Kim I.K., et al. Proapoptotic effects of tau cleavage product generated by caspase-3. Neurobiol. Dis., 2001, 8, 162-172.

[120] Nacharaju P., Ko L., Yen S.H. Characterization of in vitro glycation sites of tau. J. Neurochem., 1997, 69, 1709-1719.

[121] Horiguchi T., Uryu K., Giasson B.I., et al. Nitration of tau protein is linked to neurodegeneration in tauopathies. Am. J. Pathol., 2003, 163, 1021-1031.

[122] Halverson R.A., Lewis J., Frausto S., Hutton M., Muma N.A. Tau protein is cross-linked by transglutaminase in P301L tau transgenic mice. J. Neurosci., 2005, 25, 1226-1233.

[123] Takahashi K., Ishida M., Komano H., Takahashi H. SUMO-1 immunoreactivity co-localizes with phospho-Tau in APP transgenic mice but not in mutant Tau transgenic mice. Neurosci. Lett., 2008, 441, 90-93.

[124] Schweers O., Mandelkow E.M., Biernat J., Mandelkow E. Oxidation of cysteine-322 in the repeat domain of microtubule-associated protein tau controls the in vitro assembly of paired helical filaments. Proc. Natl. Acad. Sci. USA, 1995, 92, 8463-8467.

[125] Bukau B., Weissman J., Horwich A. Molecular chaperones and protein quality control. Cell, 2006, 125, 443-451.

[126] Weissman A.M., Shabek N., Ciechanover A. The predator becomes the prey: regulating the ubiquitin system by ubiquitylation and degradation. Nat. Rev. Mol. Cell Biol., 2011, 12, 605-620.

[127] He C., Klionsky D.J. Regulation mechanisms and signaling pathways of autophagy. Annu. Rev. Genet., 2009, 43, 67-93.

[128] Lamark T., Johansen T. Aggrephagy: Selective disposal of protein aggregates by macroautophagy. Int. J. Cell Biol., 2012, 736905. 